\title{
Hunt for cosmic rays offers scope for Africa
}

David Adam, London

As the World Summit on Sustainable Development was set to wrap up in Johannesburg this week, astronomers are heading to southern Africa for the opening of a $\gamma$-ray telescope in Namibia. And they hope that the project will serve, in its own small way, as an example of how to build bridges between science in Europe and Africa.

The instrument is the first of an array of four telescopes - called the High Energy Stereoscopic System (HESS) — that will indirectly observe the Galactic sources of cosmic rays. The telescopes will search for faint light called Cerenkov radiation, which is emitted when $\gamma$-rays pass through the Earth's atmosphere.

Cosmic rays release large numbers of $\gamma$ rays early in their life, so tracking the $\gamma$-rays could help researchers locate the source of cosmic rays (see News Feature on page 12). In contrast with the charged cosmic rays, $\gamma$ rays are uncharged and always travel through space in a straight line, making them a useful surrogate for the observation of cosmic rays.

But as well as shedding light on a range of extreme cosmic environments, such as

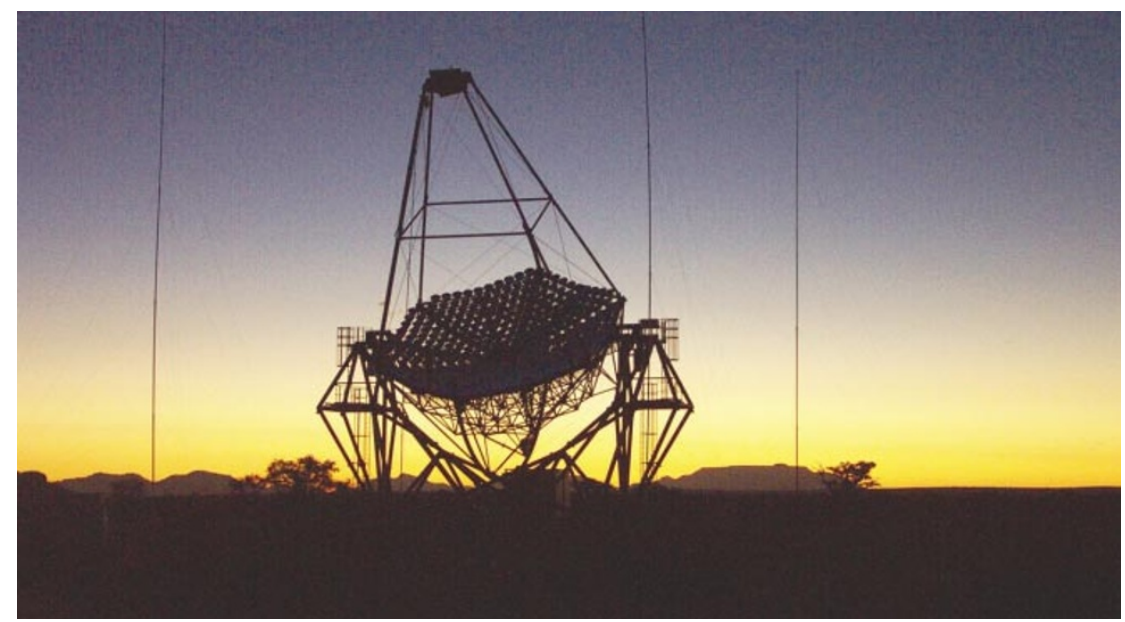

Watching brief: the HESS telescope will study cosmic rays by tracking the $\gamma$-rays that they release.

supernovae, the new facility, which is located about $100 \mathrm{~km}$ southwest of Windhoek, could boost opportunities for local scientists. The physics department at the University of Namibia in Windhoek is a partner in the 7.6-million euro (US\$7.5-million) project, which is being led by the Max Planck Institute

\section{Norway sinks ocean carbon study}

Jim Giles, London

Pressure from environmental groups looks set to scupper an international research team's attempt to test the feasibility of sequestrating large volumes of carbon dioxide in the ocean.

The Norwegian government has intervened to block the proposed release of 5 tonnes of liquefied $\mathrm{CO}_{2}$ off its coast. Three months ago, the researchers' plan to carry out the same experiment on a larger scale near Hawaii was abandoned in the face of environmental objections (see Nature 417 , 888; 2002).

Now the team - which includes engineers, oceanographers and ecologists from the United States, Norway, Japan and Canada - is running out of options and may have to abandon the idea altogether. That would be a major blow to global efforts to pursue oceanic carbon sequestration as a possible response to global warming - and a big victory for green groups, some of whom regard sequestration as a diversion from the need to cut $\mathrm{CO}_{2}$ emissions.

The scientists had planned to release the $\mathrm{CO}_{2}$ at a depth of 800 metres, and monitor its impact on the Norwegian Sea, to investigate whether the ocean could absorb much larger volumes of $\mathrm{CO}_{2}$ from power plants, for example.
A permit for the experiment was granted by the Norwegian Pollution Control Authority on 5 July. But Børge Brende, the Conservative Party environment minister in Norway's coalition government, decided to review the authority's decision after protests from Greenpeace and the World Wide Fund for Nature. The ministry announced on 22 August that the project would not go ahead.

"We think it should be researched and a decision made on the science," complains one of the researchers, Eric Adams, a hydrodynamicist at the Massachusetts Institute of Technology. "This is politics meddling with science," he says.

The pressure groups argued that the experiment would contravene oceanpollution treaties. They also object to any large-scale release of $\mathrm{CO}_{2}$ into the oceans, claiming that it could damage marine ecosystems and would eventually leak back to the atmosphere. Researchers counter that the experiment was designed precisely to investigate whether such fears are justified.

The team is considering what to do next. Adams says they could do the work quite legally in international waters, although most are too deep for this study. The second delay has also complicated matters with the project's funders, as the original time-frame for the experiment has now expired. for Nuclear Physics in Heidelberg, Germany.

Riaan Steenkamp, a cosmic-ray physicist at the University of Namibia, hopes that the arrangement will mean funding for more students in his department. "It's a stroke of luck that they decided to build this in Namibia," he says. "I'm currently the only guy here trained in a relevant field but I hope that within a year or so we can establish a small group."

Student exchange schemes with universities in France and Germany have already been set up, he says, and access to the telescopes could help the university win cash from a new space-science programme in neighbouring South Africa. The telescopes have also sparked national interest - the Namibian Post Office has issued a stamp commemorating its construction, painted by local artist J. J. van Ellinckhuijzen.

In the past, astronomers have been criticized for setting up observatories in the developing world — particularly in Chile that didn't reach out to local communities, universities or scientists. HESS is being billed as a European-African collaboration by its European sponsors, although the University of Namibia is one of just two partners actually based in Africa, the other being the University of Potchefstroom in South Africa.

"The Europeans were sensitive because of what happened in South America, so they made it a point to involve us," Steenkamp says. Telescope sites in the Southern Hemisphere are popular with astronomers based in the north because they allow them to view different parts of the cosmos, including the centre of our Galaxy.

The first HESS telescope, which was due to be inaugurated on 3 September, should produce its first useful data by the end of the year. The other three telescopes that will make up the array are expected to open by the end of next year. 